\title{
Atuação política e educação não-formal na cibercultura: a construção do sujeito tensional fora dos espaços institucionais da educação tradicional
}

Eugênio Rondini Trivinho

Professor do Programa de Estudos Pós-Graduados em Comunicação e Semiótica da PUC-SP (Departamento de Artes da Faculdade de Filosofia, Comunicação, Letras e Artes)

E-mail: eugeniotrivinho@uol.com.br

Lilian Venturini Gavaldão

Mestre em Comunicação e Semiótica pela Pontifícia Universidade Católica de São Paulo (PUC-SP). E-mail:venturini.lilian@gmail.com

Resumo: $\bigcirc$ artigo aborda as possibilidades da educação não-formal na cibercultura, tida como fase atual da civilização multimediática. Entrelaçando teoria da socialização e sociologia da educação, a reflexão objetiva apurar até que ponto contextos não-institucionalizados de formação, mediados por tecnologias digitais e redes interativas, contribuem, de fato, para a construção de um sujeito tensional - processo concebido como experiência cotidiana influenciada o menos possível por valores tecnicistas, econômico-utilitários e burocrático-funcionalistas, tão característicos dos últimos séculos. Apoiado no conjunto de ações digitais dos coletivos Transparência Hacker e Ônibus Hacker, o estudo explora as características, o desenvolvimento e as armadilhas dessa experiência de formação política e crítica, consolidada fora dos espaços escolares convencionais.

Palavras-chave: cibercultura; comunicação; socialização; educação não-formal; tecnologias digitais.
Abstract: Our article approaches nonformal education possibilities in cyberculture, understood as the present phase of multi-media civilization. The investigation aims at determining to what extent noninstitutionalized contexts of education, mediated by digital technologies and interactive networks, really contribute to developing a countercultural individual. The reflection understands this process as a daily experience influenced as little as possible by technical, economic-utilitarian, and bureaucratic-functionalist values. Our study is supported both by the theory of socialization and by the sociology of education. Based on the Transparency Hacker and Hacker Bus groups' digital actions, our argumentation explores the characteristics, development, and pitfalls of the experience of political and critical education obtained outside conventional school environments.

Keywords: cyberculture; communication; socialization; non-formal education; digital technologies. 
comunicação \& educação • Ano XXV • número 2 • jul/dez 2020

\section{INTRODUÇÃO}

Há séculos, áreas distintas do conhecimento debruçam-se sobre o desafio de compreender a relevância do sujeito no processo histórico. Tendo em perspectiva o mesmo interesse, convém operar relativa inversão nos termos da equação, com foco prioritário na dimensão educativa: de que forma o momento histórico presente, fincado na proliferação de tecnologias digitais e redes interativas e na aceleração dos processos práticos, possibilita a formação do sujeito no seio da vida cotidiana?

A natureza sociotecnológica dessa condição histórica, aqui compreendida como cibercultura - fase contemporânea do capitalismo tardio e já desdobrada como civilização mediática avançada -, nutre-se da velocidade propriamente digital como vetor macroestrutural de organização da vida humana em todos os setores, desde a esfera da produção à do tempo livre e de lazer.

A articulação dos fatores sociotecnológicos que definem a cibercultura conforma-se como lógica com largo valor axiomático, capaz de otimizar e reescalonar o primado da técnica como macrocondição imperativa (e implacável) de pertencimento sociocultural do indivíduo.

Embora enfoques similares tenham sido consumados em fases pregressas do capitalismo (desde a sua fase industrial), recolocá-los, de modo diverso, no contexto social-histórico da cibercultura, permite abranger especificidades de época capazes de enriquecer e reposicionar o debate público, dentro e fora da área de educação, para além do mero uso pedagógico de "ferramentas" à disposição. Esse direcionamento prioriza a dúvida sobre se, por meio desses instrumentos, seria possível tornar o indivíduo alguém consciente e questionador de aspectos imperceptíveis do âmbito social em que está inserido, em paralelo ao conservadorismo do senso comum, e, portanto, contribuir para a construção ou robustecimento de visões de mundo diferentes das desse estrato de percepção. Essa dúvida pressupõe - e não constitui equívoco afirmá-lo - que as tecnologias digitais e redes interativas integram a camada mais superficial, embora jamais desimportante, de uma dinâmica social cuja “desmontagem” permite conhecer, na imanência, não somente o seu modus operandi, mas também as suas contradições e, com isso, identificar os processos de formação nela existentes.

O foco na dimensão social-histórica do desenvolvimento tecnológico atual - dimensão prioritária no presente estudo - faz o interesse sobre o potencial formativo na e da cibercultura repousar nos chamados ambientes não-formais. Nesses espaços, desencadeados com apoio em tecnologias digitais, a construção do conhecimento ocorre mediante troca de saberes e experiências protagonizados pelos próprios indivíduos responsáveis pela articulação desses espaços, sem interferência censória direta das instituições herdadas da modernidade política. Essa delimitação não é aleatória. Justifica-se pela percepção de que, a exemplo do processo de socialização, de trabalho e de lazer, bem como da produção e circulação de bens culturais, a educação passou por profundas transformações que acabaram por remodelar o conjunto de valores sobre o 
qual ela se alicerça. Esse fato torna enfoques heterodoxos não apenas legítimos, como também necessários.

Nessa direção, Graça Setton ${ }^{1}$ resgata a ideia de reflexividade proposta por Anthony Giddens - a saber, o constante exame e a reformulação das práticas sociais à luz do conhecimento e das informações disponíveis - para elaborar o seu entendimento acerca da socialização na atualidade. A autora encara a socialização como um processo implicado na e abrangido pela articulação de diferentes instâncias e agentes sociais, numa dinâmica constante em que, na regra da normalidade, o indivíduo, sem ser inteira vítima das condições vividas, negocia com elas; independentemente de serem mais ou menos fragmentadas, com legibilidade e compreensão comprometidas em algum sentido. Essa perspectiva reconhece que, em parte devido ao fim do monopólio das instâncias socializadoras tradicionais, o sujeito joga papel relevante (embora não absoluto) na construção de sua própria socialização: sua participação constante intervém, de alguma forma, em seu destino social e nas condições vividas, para além de ser mero e bom condutor da troca de bens simbólicos e, em especial, de informações.

Esse princípio do primado da socialização desmonopoliza o processo educacional do sujeito. A premissa exige que o conceito de formação, no âmbito do desenvolvimento cognitivo individual, subordine-se à experiência cotidiana em vez de somente à aprendizagem institucionalizada. Essa descentralização do processo de formação inspira-se nas conhecidas reflexões de Theodor W. Adorno $^{2}$ sobre educação: a experiência na cultura mais aberta detém poder de grande forja. É desse modo que Setton compreende a razão de ser da prática educativa, a saber,

[...] não apenas como o processo de aprendizagem de um conhecimento formal e sistemático, mas também como uma prática que está presente de maneira difusa e pulverizada no cotidiano das relações sociais, sobretudo no conhecimento pulverizado e possibilitado pelo crescimento da circulação de informações ${ }^{3}$.

\subsection{Exemplos empíricos de fundamentação}

A sistematização desses apontamentos justifica, por sua tendência, a escolha como exemplos empíricos de fundamentação do presente estudo - de dois coletivos ligados à práxis da cultura digital: a Transparência Hacker e o Ônibus Hacker . As ações deles envolvem, essencialmente, a apropriação e o manejo políticos das tecnologias e redes interativas em favor do interesse social. Nessa operação, patenteiam-se, simultaneamente, tanto efeitos educativos sobre os destinatários das ações quanto o enquadramento dos próprios agentes num frutífero processo de aprendizagem - tudo em espaço externo à instituição escolar.

$\mathrm{Na}$ experiência sociocultural tecnologicamente mediada e protagonizada por ambos os coletivos, os integrantes cambiam saberes e procuram gestar novas formas de atuação política. Esse processo é espontaneamente articulado
1. SETTON, Maria da Graça Jacintho. A particularidade do processo de socialização contemporâneo. Tempo Social, São Paulo, v. 17, n. 2, p. 335-350, 2005; Idem. A noção de socialização na sociologia contemporânea: um ensaio teórico. São Paulo: [s. n.], 2008; Idem A socialização como fato social total: notas introdutórias sobre a teoria do habitus. Revista Brasileira de Educação, Rio de Janeiro, v. 14, n. 41, p. 296-307, 2009; Idem. Teorias da socialização: um estudo sobre as relações entre indivíduo e sociedade. Educação e Pesquisa, São Paulo, v. 37, n. 4, p. 711-724, 2011.

2. ADORNO, Theodor W. Educação e emancipação. Rio de Janeiro: Paz e Terra, 1995; Idem. Teoria da semicultura. Educação e Sociedade, Campinas, v. 17, n. 56, p. 388-411, 1996.

3. SETTON. Op. cit., 2005 p. 337-338.

4. O primeiro coletivo foi iniciado em 2009 e permanece ativo até hoje. Seu fórum na Internet conta com mais de 2 mil participantes, em intenso compartilhamento de informações, ideias e iniciativas. O Ônibus Hacker, iniciado em 2011, percorreu o país promovendo oficinas sobre diversos temas. Em meados de 2018, o projeto precisou ser interrompido. Em razão da natureza temática e dos objetivos deste artigo, a suspensão de tais atividades não invalida a remissão à experiência tecnoeducativa desse coletivo como corpus emblemático. 
5. GADOTTI, Moacir. A questão da educação formal/não-formal. In: INS TITUT INTERNATIONAL DES DROITSDE L'ENFANT. Droit à l'éducation: solution à tous les problèmes sans solution? Sion: 2005. p. 1-11; GOHN, Maria da Glória. Educação não-formal: um novo campo de atuação. Ensaio: Avaliação, Políticas Públicas e Educação, Rio de Janeiro, v. 6, n. 21, p. 511-526, 1998; Idem. Educação não-formal e cultura política: impactos sobre o associativismo do terceiro setor. São Paulo: Cortez. 1999; Idem. Não-fronteiras: universos da educação não-formal. São Paulo: Itaú Cultural, 2007.

6. LANDOWSKI, Eric Aquém ou além das estratégias, a presença contagiosa. Documentos de Estudo do Centro de Pesquisas Sociossemióticas, São Paulo, n. 3, p. 11-50, 2005a Idem. De l'imperfection, o livro do qual se fala. In GREIMAS, Algirdas J. Da imperfeição. São Paulo: Hackers, 2002. p. 125-150; Idem. O olhar comprometido. Galáxia São Paulo, v. 2, p. 19-56, 2001; Idem Para uma semiótica sensível. Educação \& Realidade, Porto Alegre, v. 30, n. 2 , p. 93-106, 2005b.

7. MAGNANI, José GuiIherme C. De perto e de dentro: notas para uma etnografia urbana. Revista Brasileira de Ciências Sociais, São Paulo, v. 17 n. 49, p. 11-29, 2002.

8. Dados os objetivos do presente estudo, o traba-

Iho analítico centrou-se nas ações dos membros mais ativos de ambos os grupos, descartando qualquer incursão de pesquisa junto ao público destinatário das atividades por eles desenvolvidas. Tal universo, além de escapar ao recorte prioritário do momento, demandaria investigação mais delongada. entre os membros dos grupos, de forma horizontal e não sistematizada, com objetivos voltados à divulgação à apreensão de valores culturais e sociais sem a preocupação com formação técnica e/ou profissionalizante. Essa práxis se enquadra na definição de educação não-formal proposta por Moacir Gadotti e Maria da Glória Gohn ${ }^{5}$.

Em justa medida, essas notações não contextualizam senão o quanto os já mencionados coletivos, além de experiências evidentes de socialização, constituem espaços de formação; e que, apesar de suas atividades dependerem de tecnologias e redes digitais, ligadas majoritariamente a usos sociais conservadores e/ou inconscientes, tal mediação, ao contrário, potencializa a formação crítica do indivíduo antes de dificultá-la, deformá-la ou impedi-la.

$\mathrm{Na}$ trilha de pesquisa realizada, a verificação dessas proposições apoiou-se metodologicamente em procedimentos analíticos tanto da semiótica discursiva como da etnografia, com resultados bem-sucedidos. As duas vertentes, admitindo influência do contexto social-histórico no objeto de investigação, enriqueceram o resultado reflexivo do estudo feito ao sobrelevarem, cada qual, franjas objetais diversas para o exercício observador. A aplicação da semiótica discursiva, inspirada em Eric Landowski ${ }^{6}$, recaiu sobre textos - artigos, mensagens e vídeos - elaborados pelos integrantes dos coletivos e foi destinado a apurar valores e reiterações que permitissem reconhecer o modus operandi da respectiva construção de sentidos. A metodologia etnográfica, na perspectiva de Magnani ${ }^{7}$, inspirou o processo de coleta de informações, a realização de entrevistas e a observação participante em intervenções organizadas pelos coletivos ${ }^{8}$.

Evidentemente, a natureza e o escopo da investigação, bem como as estratégias metodológicas, exigiram levar em conta a dimensão do tempo de produção social dos efeitos da educação não-formal envolvidas. A importância desse aspecto nos estudos centrados em processos da experiência cotidiana impõe-se per se; sob pena de, em caso contrário, inconsistência e/ou incompletude comprometedora dos resultados reflexivos. Pôs-se acima de dúvida o fato de que, no âmbito das atividades desenvolvidas pelos coletivos, cada sujeito participante tende a apreender, de modo peculiar, a vivência partilhada. A percepção e subjetivação do mundo depende de lastro constitutivo prévio, o que significa que o perímetro cronológico estrito das próprias atividades acompanhadas seria, portanto, insuficiente, inconsistente e/ou impreciso como referência (por exemplo, nas entrevistas) para a avaliação dos efeitos mencionados. Em vista disso, uma variável de tempo maior foi então abrigada como incursa no objeto investigado.

Com base nos elementos sistematizados a partir do trabalho analítico e do acompanhamento diário dos coletivos por três anos, verificou-se, igualmente, até que ponto as ações traduziam-se, de fato, em valores e memórias a ponto de se configurarem como habitus típico na perspectiva de Pierre Bourdieu ${ }^{9}$. Em adição, o próprio curso da investigação validou, com efeito, o questionamento sobre o quanto a experiência construída era de fato contracultural. As razões para isso eram evidentes: o propósito político e social dos coletivos é articulado e influenciado no e pelo mesmo processo social-histórico que funda a civilização 
multimediática e que se sustenta no fio do respectivo poder comunicacional vigente, socialmente estruturado na e pela (existência de uma) ressonância infraestrutural, ideológica e operacional conservadora e permanente de media de diferentes tipos (de massa, interativos e híbridos); e o processo civilizatório aí gestado também forja um habitus, ingrediente de um sprit du temps que não deixa de envolver, com maior ou menor acento, todas as dimensões do existente.

\section{SOCIALIZAÇÃO, FORMAÇÃO E PARTICIPAÇÃO}

No lastro das mudanças estruturais apontadas, Setton ${ }^{10}$ assevera que a ação pedagógica e socializadora do sujeito, superando a exclusividade dos espaços familiar e escolar, tem incorporado, cada vez mais, elementos mediáticos (tecnológicos e simbólicos) como participantes de seu alcance e de seus resultados formativos. A crescente massificação dos fluxos de informação e bens culturais, a partir da segunda metade do século XX, contribuiu para que o processo de socialização equivalesse a uma dinâmica de ressonância mais diversa e complexa, um "espaço plural de múltiplas relações sociais"11. Em decorrência disso, posições de autoridade sofreram revisões e deslocamentos significativos, e as instituições assimilaram contornos mais heterogêneos quando comparadas a suas fases históricas pregressas. Conforme antes sinalizado, a escola, em especial, deixou de ser, formalmente, a principal organizadora das experiências do sujeito, em razão da perseverante potência com que novos atores, valores e conhecimentos passaram a ser produzidos e a circular no universo extraescolar.

Levando em conta o contexto social-histórico em que o processo educacional se insere, Setton ${ }^{12}$ equipara a socialização a uma construção cultural em que convivem práticas individuais, coletivas e institucionais. O processo abriga troca constante: além da mera transmissão de valores e de saberes, há negociação e apropriação por parte do indivíduo. Em coesão, a noção de cultura também é, no olhar de Setton, apreendida a partir de seu contexto de formação histórico, material, simbólico e moral. Essas contribuições abrem-se a tensões socialmente existentes e aos modos pelos quais, nesse contexto, a cultura é influenciada por tais conflitos, sob a pressuposição de que, na civilização multimediática em curso, a criação e disseminação de discursos, narrativas e mensagens, até a saturação, assumiu prioridade na dinâmica simbólica da cultura. O procedimento põe em evidência as diferenças sociais, o modo de produção econômico e cultural e, obviamente, as relações de poder.

A previsão dessa tensão entre sujeito e contexto é amplamente relevante na observação dos modos de atuação dos dois mencionados coletivos, a Transparência Hacker e o Ônibus Hacker. Antes, a forma pela qual ambos os grupos se organizaram e apresentaram suas ações tornou-os potentes campos de socialização. O presente estudo enfoca, com efeito, se esses coletivos participaram, tão ou mais ativamente quanto outras instituições (entre elas, a escola), do processo
9. Em sua proposta epistemológica, o sociólogo francês previu o conceito de habitus para superar a tese do divórcio a priori entre sujeito e realidade. $\bigcirc$ habitus, introjetado pelo indivíduo desde tenra idade no processo de socialização, opera como elo matricial involuntário de mediação com a sociedade. Numa definição representativa, Bourdieu (1983) designa o habitus como um sistema de "disposições duráveis, estruturas estruturadas predispostas a funcionar como estruturas estruturantes, isto é, como princípio gerador e estruturador das práticas e das representações que podem ser objetivamente 'reguladas' e 'regulares' sem ser o produto da obediência a regras, objetivamente adaptadas a seu fim sem supor a intenção consciente dos fins e o domínio expresso das operações necessárias para atingi-los e coletivamente orquestradas, sem ser o produto da ação organizadora de um regente" (p. 60-61, grifo do autor).

10. SETTON. Op. cit., $2002 b$.

11. Ibidem, p. 109.

12. Idem, 2002b; Idem, 2011. 
de constituição sociocultural de sujeitos de criticidade (no caso, os membros dos próprios grupos).

A Transparência Hacker e o Ônibus Hacker foram formados por representantes de uma geração fortemente influenciada por tendências ciberculturais e, ao mesmo tempo, articuladas segundo uma práxis sobremaneira distante do modelo hierarquizado e burocratizado das instituições herdadas; integram, mais propriamente, o "terreno social", na perspectiva de Hardt e Negri ${ }^{13}$ - um campo conflitivo a céu aberto, por assim dizer, conforme ele se joga diretamente e se confunde totalmente com a res pública das ruas e das redes digitais. Não por acaso, o conhecimento acumulado, produzido e transmitido pelos coletivos subordina-se ao arco da caracterização feita por Setton sobre o processo de socialização.

Naturalmente, a estreita ligação desses coletivos com a tecnologia digital não pode ser apreendida senão sob o prisma da crítica. Esse filtro criterioso - somente ele, aliás - abarca o vínculo inextricável entre objeto de estudo e seu contexto social-histórico. Somente essa injunção, computado o conjunto de contradições nela envolvido, possibilita visão ponderada, longe de qualquer ingenuidade política, e capaz de apreciação consistente (das bases e das possibilidades) da autoformação de um sujeito tensional em ambientes socializadores não-formais. O qualificativo "tensional” se refere à capacidade individual ou grupal de realizar uma negociação voluntária, crítica e consciente com os valores que regulam os contextos (estruturais ou conjunturais) em que os protagonistas estão inseridos. A ideia pressuposta de tensão implica camadas diferentes de engajamento e investimento de interesse: oscila desde a reserva subjetiva e a salutar suspeita cognitiva até o confronto e a ruptura éticos em relação às condições socioculturais e político-econômicas do vivido e da época, no estrato fenomenológico-objetivo e/ou corporal-subjetivo. Ambientes abertos ao contraditório e ao questionamento, dotados de meios e recursos materiais que lhes garantam desenvolvimento, numa dinâmica permanente de trocas simbólicas sem censura, favorecem, sem dúvida, o aparecimento e o robustecimento de sujeitos com as características assinaladas.

Três aspectos estruturais desse processo de formação merecem ser evidenciados: primeiro, as condições objetivas de constituição pessoal da bagagem cognitiva - o principal valor, nesse aspecto, é o acesso sociotecnológico a todo tipo de conteúdo, especialmente o de caráter crítico, necessário à elaboração de uma visão de mundo mais autônoma possível, alerta tanto às suas fragilidades quanto às cooptações do contexto imediato; em segundo, esse processo educativo se realiza sob significativa desburocratização: independentemente de ambiente ou métodos sistematizados e/ou institucionalizados, remete a uma experiência fincada no cotidiano, no coletivo, sob ciência das potencialidades dos recursos interativos da civilização mediática avançada; terceiro, esse entendimento corrobora a atribuição ao sujeito (e não somente às instituições) a responsabilidade pela interferência nos destinos o mundo. 
Neste ponto vale, em retomada, articular o entendimento de Setton ${ }^{14}$ sobre a socialização com o de Gadotti sobre a educação não-formal ${ }^{15}$. Setton busca em Bourdieu (na teoria do habitus) e em Giddens (na leitura da modernidade em ruína) referências capazes de definir a possibilidade de um sujeito na configuração social-histórica e tecnocultural emergente. Cotejando a participação individual com a pluralidade de estímulos e de referências típicos do mundo mediático atual, Setton entrevê um sujeito cuja identidade é forjada a partir de um "habitus híbrido" mente trilhado no âmbito das instituições tradicionais. Essa arquitetura peculiar do processo de socialização revê, por consequência, os modos de construção e aquisição de conhecimento. No espaço multimediático da cibercultura, tais práticas se enquadram no modelo de educação não-formal vislumbrado por Gadotti e por Gohn. O primeiro prioriza "a educação não-formal por [...] sua especificidade e não por sua oposição à educação formal”" apontando que a escultura não-formal do processo educacional

[...] é mais difusa, menos hierárquica e menos burocrática. Os programas de educação não-formal não precisam necessariamente seguir um sistema sequencial e hierárquico de "progressão". A educação não-formal é também uma atividade educacional organizada e sistemática, mas levada a efeito fora do sistema formal ${ }^{18}$.

Gohn, por sua vez, caracteriza a educação não-formal por remissão à dimensão da cultura ${ }^{19}$. Essa vinculação assimila a educação a uma dinâmica de transmissão cognitiva e de aprendizagem fincada no processo de socialização e marcada por valores de grupo, contexto social ou época. Desse ponto de vista, nada impede que práticas de educação não-formal sejam realizadas por distintas instâncias ou protagonistas, como partidos políticos, sindicatos, associações, ONGs, movimentos sociais, entre outros. A autora assevera que a educação não-formal encerra "espaço concreto de formação com a aprendizagem de saberes para a vida em coletividade" ${ }^{20}$. Não por acaso, esse tipo de formação abrange

[...] questões que dizem respeito ao dia-a-dia dos participantes. O principal objetivo dessa corrente educativa é a formação de cidadãos aptos a solucionar problemas do cotidiano, desenvolver habilidades, capacitar-se para o trabalho, organizar-se coletivamente, apurar a compreensão do mundo à sua volta e ler criticamente a informação que recebem ${ }^{21}$.

No rastro dessas sinalizações, as atividades realizadas pelo Ônibus Hacker, por exemplo, equivaliam a atividades educativas devido à sua intencionalidade pedagógica e de transmissão cognitiva. Por certo, os projetos desenvolvidos não deixavam de contratar, em medida ponderada, alguma característica formal. Inexiste, porém, subordinação a uma diretriz educacional centralizada; o espaço para aprendizagem era diverso, ora sendo uma rua ou praça, ora o próprio ônibus (que designa o grupo), ora ainda uma sala de aula - consequência da curiosidade de professores em levar a proposta para o ambiente escolar.

O destaque à educação não-formal e à aprendizagem fora de ambientes institucionalizados, além de escolha metodológica, constitui caminho natural,
14. SETTON. Op. cit 2002a; Idem. Op. cit. 2005; Idem. Op. cit. 2008; Idem. Op. cit. 2009; Idem. Op. cit. 2011.

15. GADOTTI. Op. cit., 2005 16. SETTON. Op. cit. 2002a. p. 66

17. GADOTTI. Op. cit., 2005. p. 2.

18. Ibidem, p. 2.

19. GOHN. Op. cit., 1998

20. Ibidem, p. 14

21. Ibidem, p. 14. 
quando se leva em consideração, em conjunto, a dinâmica sociotecnológica e informacional da cibercultura e, em particular, seus desdobramentos multilaterais nas relações sociais. Obviamente, essa ênfase - dispensável seria dizê-lo - não significa subtração de valor social e político à instituição escolar ou à (natureza da) educação formal, muito menos que a escola tenha perdido função formadora. Da mesma maneira, o procedimento tampouco subordina a escolarização tradicional a processos de educação não-formal (e vice-versa) ou concede aos últimos hegemonia de época. A questão se reduz a uma exigência teórica de reconhecimento objetivo: a educação formal, por mais dilatado e flexível que possa tornar-se o seu imaginário, não consegue responder sozinha às especificidades socioculturais e políticas da civilização multimediática num momento histórico de socialização difusa, com todos os efeitos de dispersão e déficit de atenção envolvidos. Resulta, pois, evidente, também, que a questão da formação (incluindo a reflexão sobre ela) precisa transcender a circunscrição das práticas educativas tradicionais.

\section{CONSTRUÇÃO DE SENTIDO EM AMBIENTE COLETIVO}

A atuação dos membros da Transparência Hacker, calcada na interação com as tecnologias e redes digitais, abarca o acesso e o manejo de dados governamentais e a transformação deles em informação de utilidade pública. A atuação pressupõe, por exemplo, conhecimento em programação e desenvolvimento de projetos para a rede. Essa habilidade não é, porém, condição indispensável para envolver-se nas atividades, embora popularizá-la esteja entre os objetivos do grupo. O Ônibus Hacker, por sua vez, dedicou-se inicialmente a atividades ligadas a aprendizado e empoderamento tecnológicos. Aos poucos, inseriu oficinas sobre questões extradigitais referentes ao meio ambiente, ao sistema político brasileiro e à arte, além de outras. Ainda assim, para ambos os coletivos, a tecnologia sempre foi crucial - trata-se, nas palavras dos protagonistas, de uma ferramenta com potencial amplamente catalizador em processos de troca e construção de saberes.

A articulação das atividades com propostas de ação política e práticas off-line, ao conduzir a relação com a tecnologia para além dos limites do interesse técnico, faz de cada coletivo um espaço socializador de saberes e sentidos ciberculturais em que se misturam valores, condições e agentes não observáveis em ambientes de educação formal.

Apesar de interligados (inclusive com partilha de membros), a Transparência Hacker e o Ônibus Hacker desenvolveram, como grupos autônomos, formas diferentes de atuação. Essa especificidade entrega distintos dados para análise. A análise semiótica repousou sobre os elementos mais seletos e representativos: a lista de e-mails trocados entre 2011 e 2013, as propostas de oficinas realizadas e o vídeo em que os membros do Ônibus Hacker pedem apoio financeiro para a compra do veículo. Com base no conjunto de valores, práticas, sujeitos 
e estratégias de ação anunciado nesse corpus, granulados num processo de interação contínua entre os integrantes e seus destinatários, a reflexão restou mais bem fundamentada com a previsão da dimensão estésica envolvida. Landowski ${ }^{22}$ entrevê essa possibilidade ao ponderar sobre a natureza dos objetos dinâmicos, apreendidos apenas enquanto em ato - como as práticas sociais - à diferença de manifestações estáticas; como um afresco, uma escultura ou o texto de um romance. $\mathrm{O}$ embasamento na fenomenologia, em especial a de Merleau-Ponty, permite, segundo o sociossemioticista, apreender a significação na e da experiência do vivido a partir da dinâmica da relação entre os sujeitos. O vivido, mostra essa visada, é o vórtice em que se entrelaçam o componente ético (de ethos, ser e estar no mundo) e a dimensão estésica ${ }^{23}$.

Para compreender os dois coletivos, é necessário, portanto, focar o seu fazer político como valor per se, tal suas presença e influência no cotidiano dos agentes envolvidos. Essa ação dista da política partidária, disputativa do exercício de poderes convencionais - e tampouco equivale à de uma organização institucional. Os processos, debates e, sobretudo, mudanças de que fala a Transparência Hacker, todos entrelaçados sob o compromisso da diversidade de opiniões e posicionamentos, evocam a compreensão de Hannah Arendt sobre a política como construção social à luz do exercício permanente da liberdade, da garantia do convívio sem violência, enfim, à possibilidade de vida pacífica no âmbito tanto da relação entre indivíduos quanto da sociedade em geral. $\mathrm{O}$ celeiro da política, para Arendt, é a interação, conste ele no espaço institucional ou não. "A políticasurge no intraespaço e se estabelece como relação", diz a filósofa germânico-americana ${ }^{24}$.

Além dessa sociabilidade identificada no e com o vetor político, preexiste, na prática dos coletivos, a força do "estar com", do "estar junto", de que fala Maffesoli $^{25}$, estesia de afeto e liga entre os sujeitos e, por conseguinte, de criação de atmosfera plena, como lócus de que promana o sentido de um modo imediato e sensível ${ }^{26}$. A essa sensibilidade, comparecem atrelados os valores operados de empoderamento, de comunidade, atuação em rede etc. - essenciais para a compreensão da dimensão ética envolvida, uma vez que qualificam o percurso dos sujeitos e ressemantizam social e politicamente os fatores que os atam ao comum - a tecnologia digital, o ciberespaço e os dados públicos.

\section{ESPAÇOS DE TENSÃO, DIMENSÃO ESTÉSICA E FORMAÇÃO}

Numa reflexão sobre objeto tão dissoluto na espiral mediática instantânea, a preocupação quanto à mobilização de teorias que abarcam a dimensão social-histórica dos processos vividos, além de blindar a argumentação em relação a inconsistências macrocontextuais, fragilidades teóricas e/ou ingenuidades políticas, contribui para o mister de se descobrir qual tipo de formação está em
22. LANDOWSKI. Op. cit. 2005a; Idem. Op. cit., 2001; Idem. Op. cit.,2005b.

23. Amatéria é desdobrada no próximo tópico.

24. ARENDT, Hannah. O que é política? Rio de Janeiro: Bertrand Brasil, 1998, p. 23

25. MAFFESOLI, Michel. O tempo das tribos: o declínio do individualismo nas sociedades de massa. Rio de Janeiro: Forense Universitária, 1987, p. 101-142.

26. LANDOWSKI. Op. cit., 2001. p. 40 
jogo. A escala dessa perspectiva permite apreender aspectos macroestruturais problemáticos no recorte estudado.

Conforme assinalado, parte dos membros da Transparência Hacker era usuário avançado de tecnologias e redes digitais. Embora esses recursos sejam compreendidos e apropriados sob evidente prisma politizado, a relação para com eles, deve-se reconhecer, não deixa de se concretizar mediante utilização de ingredientes estruturais típicos da cibercultura, como, por exemplo, a interatividade, o tempo real (on-line ou streaming) e a dromoaptidão (cognitiva e procedimental) necessária à inclusão na época. Do ponto de vista da reprodução social-histórica do modelo tecnológico de vida social vigente, tais ingredientes não deixam de alicerçar o conservadorismo cultural inevitável (não raro, involuntário e/ou inconsciente), que naturalmente não se realiza sem referendo tácito aos próprios interesses e valores implicados na postergação social-histórica da cibercultura.

Esse reconhecimento acerca do modus operandi da civilização mediática avançada como relativamente inescapável não envolve aceitação de ausência de tensões internas a ela. A sociabilidade contracultural e a educação não-formal são horizontes não somente possíveis - são também viáveis. O vínculo imanente dos dois coletivos com os fatores infraestruturais da dinâmica da cibercultura, especialmente no que diz respeito ao uso heterodoxo das tecnologias e redes digitais, ao invés de desestimular ou invalidar, instigou, aliás, a própria investigação das possibilidades de formação crítica em ambientes extrainstitucionais.

Os propósitos que nutrem as atividades dos grupos radicam, evidentemente - não é demais recordar -, num entendimento heterodoxo sobre o papel político e social das tecnologias e redes digitais, além de sua mobilização segundo valores distantes dos ancorados no e fomentados pelo modelo de razão e senso comum conservadores - como o consumo (na qualidade de prática autocentrada, sem causa maior que ele mesmo), a satelitização reprodutora da espiral simbólica da produção mediática massificada e, no campo da educação institucionalizada, o aprendizado preocupado meramente com a formação de mão de obra especializada. Além disso, o posicionamento ideológico da Transparência Hacker e do Ônibus Hacker é, conforme visto, construído por meio da experiência peculiar desenvolvida por e entre seus integrantes, cuja vivência se alinha a mensagem socializadora (na prática coletiva) bem como à ressignificação do espaço público e do papel das instituições - arranjo que recobra muito pouco o discurso orientado pelo e para o mercado, pela e para a técnica per se, à sombra do poder comunicacional vigente e de seu discurso publicitário. A formação aberta, fora dos bancos escolares convencionais, ocorre sob lastro articulatório em instâncias sociopolíticas alternativas, repertórios grupais e trajetórias individuais; efetiva-se no vivido, no circuito subjetivo e afetivo de cada sujeito, e desse ponto da práxis cotidiana reverbera novamente para o coletivo, que, por sua vez, repercute efeitos em retorno num processo contínuo de trocas simbólicas ${ }^{27}$. A impossibilidade de rompimento cabal com as condições sociais regidas pela lógica cibercultural vê-se compensada pela 
negociação contextualmente autoelaborada pelo conjunto dos sujeitos, em conexão tensional com o momento histórico presente.

A análise de discurso centrada na produção (verbal e não verbal) dos integrantes de ambos os grupos detectou que a construção de sentido de suas práticas, como forma de contribuição às comunidades em que atuam, processa-se sobremaneira na dimensão do sensível, ancorada, fundamentalmente, nos valores defendidos e nas ações desenvolvidas pelos agentes. Vigora, nessa dimensão estésico-axiológica, um princípio ético que prescinde de explicação verbal (recorrente ou pontual) e que questiona, se não a lógica macroestrutural predominante no capitalismo, ao menos tonicamente algumas de suas mais importantes camadas sob a intensa preocupação de não ceder a pressões políticas e/ou econômicas, de par com o objetivo de transmitir estratégias de mudança nas regras do establishment e/ou de neutralizar seus valores conservadores.

\section{CONSIDERAÇÕES FINAIS}

A argumentação do presente texto demonstra que a educação não-formal, mediada por materiais e objetos infotecnológicos, se politizada, pode fazer frente ao conservadorismo das práticas da cibercultura contra as próprias tendências que essa época engendra em prol de seu desdobramento no tempo histórico. $\mathrm{O}$ potencial tensional vislumbrado nesse contexto formativo constitui ingrediente sine qua non de produção social de autonomia, desenvolvida diretamente no vivido sem norteamento (ou, ao menos, sem ser muito pautado) pela agenda axiomática hegemônica dos universos institucionalizado, mercadológico e publicitário.

Obviamente, a percepção das ações da Transparência Hacker e do Ônibus Hacker sob essa perspectiva, não contrata presunção de modelo programático de formação a ser seguido e/ou implementado; tampouco sinaliza que deva haver tal cartilha. O objetivo precípuo do estudo foi mobilizar recursos teórico-conceituais, fatores empírico-pragmáticos e exemplos emblemáticos para demonstrar, de modo fundamentado (ainda que em caráter preliminar), que o potencial manifesto e/ou presumido na infraestrutura sociotecnológica da cibercultura, na forma espalhada dos objetos digitais e redes interativas, permitiu emergir, dialeticamente, no social-histórico - práticas heterodoxas de apropriação política e mobilização social compatíveis com a afirmação consequente de outros tipos de educação ou contextos formativos, na qualidade de contratendências de época e que, por isso, representam, em tese ou efetivamente, alternativa aos valores majoritários vigentes, em matéria de concepção de mundo, modo de ser coletivo e/ou de ação social.

O reconhecimento da potência circunscrita do sujeito e de sua ação a céu aberto como fator pragmático de cumprimento da função de tensão do cenário social-histórico corrente e de suas tendências, atribuindo-lhes relevância na formação do sujeito, envolve contrapartidas (institucionais ou não, coletivas ou individuais) para a quais é impossível resposta completa por agora. Como 
advertiu François Dubet $^{28}$, o contexto social da ação e de suas repercussões é, ao mesmo tempo, palco de distribuição desigual de recursos materiais e simbólicos (culturais, políticos, axiológicos etc.); e, no perímetro do presente estudo, reconhecer, igualmente, essa condição como pressuposto socioestrutural de ambientes educativos de caráter não-formal não deixa de implicar, de certa maneira, chancela a periclitante incapacidade do Estado e de suas instituições se inserirem de forma competente e esperada na estrutura dinâmica do processo inteiro. Esse fato não patenteia senão que a cibercultura, ao mesmo tempo que desencadeia espaço para caminhos heterodoxos, renova o caudal de armadilhas, foco para atenção prioritária em estudos subsequentes.

\section{REFERÊNCIAS BIBLIOGRÁFICAS}

ADORNO, Theodor W. Educação e emancipação. Rio de Janeiro: Paz e Terra, 1995.

ADORNO, Theodor W. Teoria da semicultura. Educação e Sociedade, Campinas, v. 17, n. 56, p. 388-411, 1996.

ARENDT, Hannah. O que é política? Rio de Janeiro: Bertrand Brasil, 1998.

BOURDIEU, Pierre. Esboço de uma teoria da prática. In: ORTIZ, Renato (org.). Pierre Bourdieu: Sociologia. São Paulo: Ática, 1983. p. 46-81.

DUBET, François. A formação dos indivíduos: a desinstitucionalização. Contemporaneidade e Educação, São Paulo, v. 3, n. 3, p. 27-33, 1998.

GADOTTI, Moacir. A questão da educação formal/não-formal. In: INSTITUT INTERNATIONAL DES DROITS DE L'ENFANT. Droit à l'éducation: solution à tous les problèmes sans solution? Sion: 2005. p. 1-11.

GOHN, Maria da Glória. Educação não-formal: um novo campo de atuação. Ensaio: Avaliação, Políticas Públicas e Educação, Rio de Janeiro, v. 6, n. 21, p. 511-526, 1998.

GOHN, Maria da Glória. Educação não-formal e cultura política: impactos sobre o associativismo do terceiro setor. São Paulo: Cortez, 1999.

GOHN, Maria da Glória. Não-fronteiras: universos da educação não-formal. São Paulo: Itaú Cultural, 2007.

HARDT, Michael; NEGRI, Antonio. Império. Rio de Janeiro: Record, 2005.

LANDOWSKI, Eric. Aquém ou além das estratégias, a presença contagiosa.

28. DUBET, François. A formação dos indivíduos: a desinstitucionalização. Contemporaneidade e Educação, São Paulo, v. 3 n. 3, p. 27-33, 1998.
Documentos de Estudo do Centro de Pesquisas Sociossemióticas, São Paulo, n. 3, p. 11-50, 2005a.

LANDOWSKI, Eric. De l'imperfection, o livro do qual se fala. In: GREIMAS, Algirdas J. Da imperfeição. São Paulo: Hackers, 2002. p. 125-150. 
LANDOWSKI, Eric. O olhar comprometido. Galáxia, São Paulo, v. 2, p. 19-56, 2001.

LANDOWSKI, Eric. Para uma semiótica sensível. Educação \& Realidade, Porto Alegre, v. 30, n. 2, p. 93-106, 2005b.

MAGNANI, José Guilherme C. De perto e de dentro: notas para uma etnografia urbana. Revista Brasileira de Ciências Sociais, São Paulo, v. 17, n. 49, p. 11-29, 2002.

MAFFESOLI, Michel. O tempo das tribos: o declínio do individualismo nas sociedades de massa. Rio de Janeiro: Forense Universitária, 1987.

SETTON, Maria da Graça Jacintho. A teoria do habitus em Pierre Bourdieu: uma leitura contemporânea. Revista Brasileira de Educação, Rio de Janeiro, n. 20, p. 60-70, 2002a.

SETTON, Maria da Graça Jacintho. Família, escola e mídia: um campo com novas configurações. Educação e Pesquisa, São Paulo, v. 28, n. 1, p. 107-116, 2002b.

SETTON, Maria da Graça Jacintho. A particularidade do processo de socialização contemporâneo. Tempo Social, São Paulo, v. 17, n. 2, p. 335-350, 2005.

SETTON, Maria da Graça Jacintho. A noção de socialização na sociologia contemporânea: um ensaio teórico. São Paulo: [s. n.], 2008.

SETTON, Maria da Graça Jacintho. A socialização como fato social total: notas introdutórias sobre a teoria do habitus. Revista Brasileira de Educação, Rio de Janeiro, v. 14, n. 41, p. 296-307, 2009.

SETTON, Maria da Graça Jacintho. Teorias da socialização: um estudo sobre as relações entre indivíduo e sociedade. Educação e Pesquisa, São Paulo, v. 37, n. 4, p. 711-724, 2011. 